\title{
Oxidation of $\mathrm{ZnO}$ thin films during pulsed laser deposition process
}

\author{
E DE POSADA ${ }^{1, *}$, L MOREIRA ${ }^{1}$, J PÉREZ DE LA CRUZ ${ }^{2}$, M ARRONTE ${ }^{1}$, L V PONCE ${ }^{1}$, \\ T FLORES ${ }^{1}$ and J G LUNNEY ${ }^{3}$ \\ ${ }^{1}$ CICATA-Instituto Politécnico Nacional, Altamira 89600, México \\ ${ }^{2}$ INESC Porto, Rua do Campo Alegre, 687, 4169-007 Porto, Portugal \\ ${ }^{3}$ School of Physics, Trinity College, Dublin 2, Ireland
}

MS received 1 March 2012

\begin{abstract}
Pulsed laser deposition of $\mathrm{ZnO}$ thin films, using $\mathrm{KrF}$ laser, is analysed. The films were deposited on (001) sapphire substrates at $400{ }^{\circ} \mathrm{C}$, at two different oxygen pressures $(0.3$ and $0.4 \mathrm{mbar})$ and two different targetsubstrate distances $(30$ and $40 \mathrm{~mm})$. It is observed that in order to obtain good quality in the photoluminescence of the films, associated with oxygen stoichiometry, it is needed to maximize the time during which the plasma remains in contact with the growing film (plasma residence time), which is achieved by selecting suitable combinations of oxygen pressures and target to substrate distances. It is also discussed that for the growth parameters used, the higher probability for $\mathrm{ZnO}$ films growth results from the oxidation of $\mathrm{Zn}$ deposited on the substrate and such process takes place during the time that the plasma is in contact with the substrate. Moreover, it is observed that maximizing the plasma residence time over the growing film reduces the rate of material deposition, favouring the surface diffusion of adatoms, which favours both $\mathrm{Zn}-\mathrm{O}$ reaction and grain growth.
\end{abstract}

Keywords. Ablation; film deposition; $\mathrm{ZnO}$ thin film; semiconductors.

\section{Introduction}

Pulsed laser deposition (PLD) is one of the widely used technique for growing thin films of multi-component materials. Among them, superconductor, ferroelectric and semiconductor materials like $\mathrm{YBaCuO}$ (Wang et al 1999), BaTiO (Xuan et al 1998) and $\mathrm{ZnO}$ (Wang et al 2003), respectively are some of the examples. $\mathrm{ZnO}$ is a well known material for its applications in solar cells and surface acoustic-wave devices. Recently, good results have been obtained using $\mathrm{ZnO}$ as a matrix for magnetic doping in the race for the development of so-called spin-electronic devices (Fukumura et al 1999) and it has emerged as an important material for developing near UV-semiconductor lasers (Tobin et al 2006) or opto-electrical devices (Li et al 2010).

The near UV-interband emission and its relation to the structural and surface properties of $\mathrm{ZnO}$ thin films, have been discussed in several papers in recent years (Tang et al 1998; Wu et al 2001). A detailed explanation on how and why $c$-oriented films are commonly obtained has been reported by Claeyssens et al (2005); while other studies have been devoted to the influence of the film thickness (Shim et al 2002), oxygen pressure (Im et al 2000; Shan et al 2005) and growth time (Vasco et al 2001) on the optical properties. In general, it is stated that the oxygen content is critical to obtain good quality films. Despite the amount of work devoted to the PLD of $\mathrm{ZnO}$ thin films, there is no clear picture about

\footnotetext{
*Author for correspondence (edeposada@ipn.mx)
}

how material formation takes place, which is of prime importance in reaching a stoichiometric growth. This article combines the characterization results of both plasmas and thin films, obtained with different growth parameters, to identify the mechanism of $\mathrm{ZnO}$ formation during the PLD process.

\section{Experimental}

A $\mathrm{KrF}$ eximer laser, with a fluence of $1 \mathrm{~J} / \mathrm{cm}^{2}$ was used to ablate a $99.99 \%$ pure $\mathrm{ZnO}$ ceramic target for $10 \mathrm{~min}$ in an atmosphere of oxygen. The films were deposited on (001) sapphire substrates at $400{ }^{\circ} \mathrm{C}$, using two different oxygen pressures and two different target-substrate distances (TSD). Some of the films were post-annealed in a deposition chamber, using the same substrate temperature and oxygen pressure as during the growth, with the aim of comparing structural and optical properties with the as-grown films.

The surface morphology of the films was examined using scanning electron microscopy (SEM) technique. A profilometer was used to measure the film thickness. X-ray diffractometer (XRD), equipped with a $\mathrm{CuK}_{\alpha}$ source and $\theta-2 \theta$ configuration, was used to study the crystalline properties of the films. The photoluminescence of the films was measured with a $\mathrm{HeCd}(\lambda=325 \mathrm{~nm})$ laser, a monochromator and a photomultiplier tube cooled to $-23{ }^{\circ} \mathrm{C}$. All the sample spectra were acquired at room temperature using a $1 \mathrm{~nm}$ step size and an integration time of $1 \mathrm{~s}$. The study of plasma expansion was performed using a planar Langmuir probe biased at $-30 \mathrm{~V}$ and a gated ICCD. A delay generator 
was used to set both the ICCD integration time $(3.8 \mathrm{~ns})$ and the delay time after laser pulse arrival to target.

\section{Results}

XRD patterns of the grown $\mathrm{ZnO}$ samples are shown in figure 1, together with the growth parameters. The strong (002) and (004) peaks show that there is a preferential growth in the direction [00] with small quantity of [00] oriented material as can be drawn from the relatively weak intensity of the (100) peak.

It can also be observed that disregarding oxygen pressure films grown at a TSD of $30 \mathrm{~mm}$ presented poorer crystalline properties, showing higher intensity in the (100) peak and smaller grain size, as calculated using the Scherrer formula,
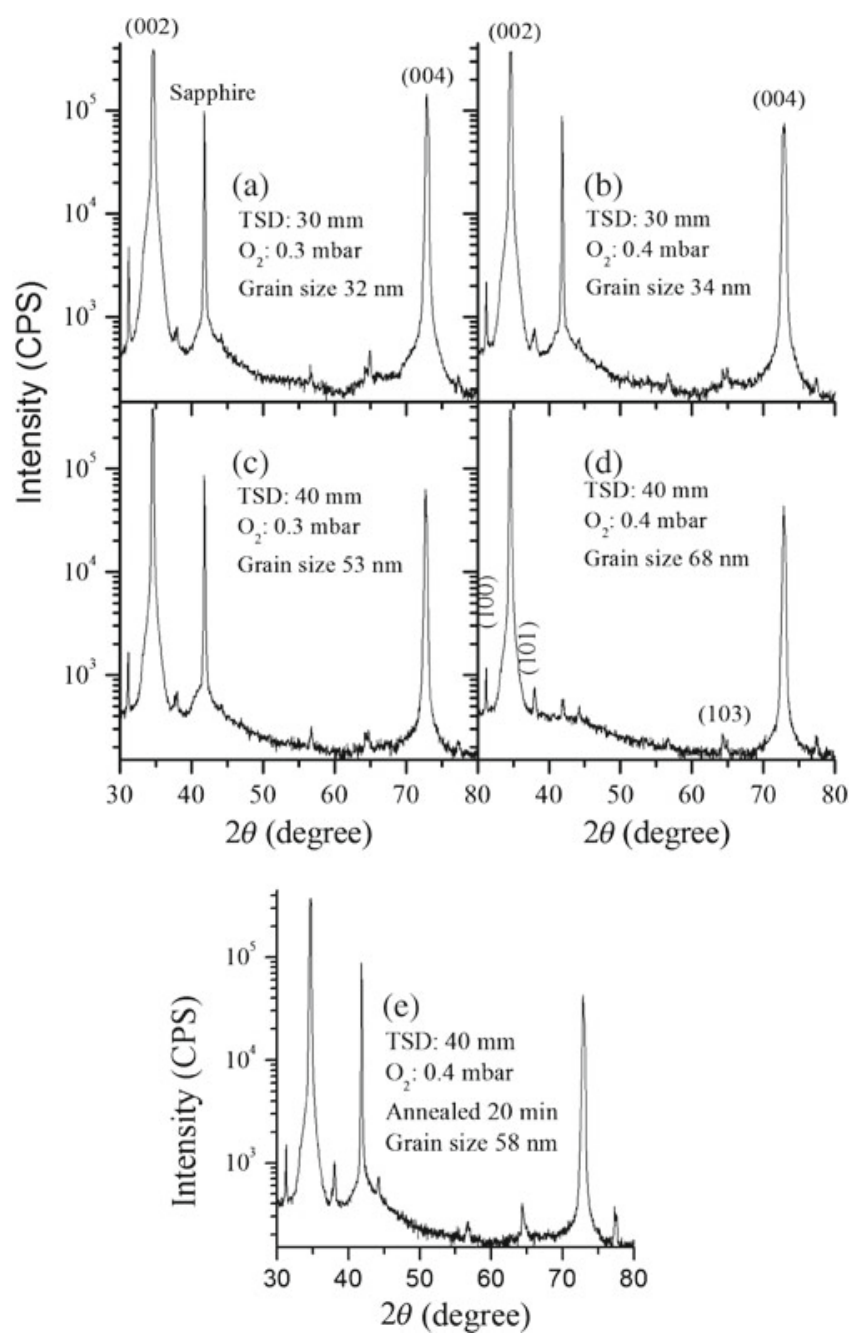

Figure 1. XRD pattern of $c$-oriented $\mathrm{ZnO}$ films and corresponding grain size, as calculated using Scherrer formula, together with growth parameters. Figures (a-d) correspond to as-grown films while figure (e) corresponds to a film annealed for $20 \mathrm{~min}$ with same oxygen pressure and temperature as used during its growth. than those obtained at a TSD of $40 \mathrm{~mm}$. The annealing process carried out to the $\mathrm{ZnO}$ film, prepared with the same conditions of figure 1(d) film, did not reveal any significant improvement on the $\mathrm{ZnO}$ film structural quality, as shown in figure 1(e).

Figure 2 shows photoluminescence (PL) spectra of the films. All the films show the expected blue band at $\sim 370 \mathrm{~nm}$ that is associated with the band-edge transition $(3.3 \mathrm{eV})$ characteristic of $\mathrm{ZnO}$. Films grown at TSD of $30 \mathrm{~mm}$ showed wide yellow-green and orange bands in the range of 450 $700 \mathrm{~nm}$, which are understood to be associated with oxygen vacancies (Im et al 2000; Shan et al 2005). The above mentioned optical bands practically disappear in the $\mathrm{ZnO}$ film prepared at a TSD of $40 \mathrm{~mm}$ with 0.3 mbar oxygen pressure
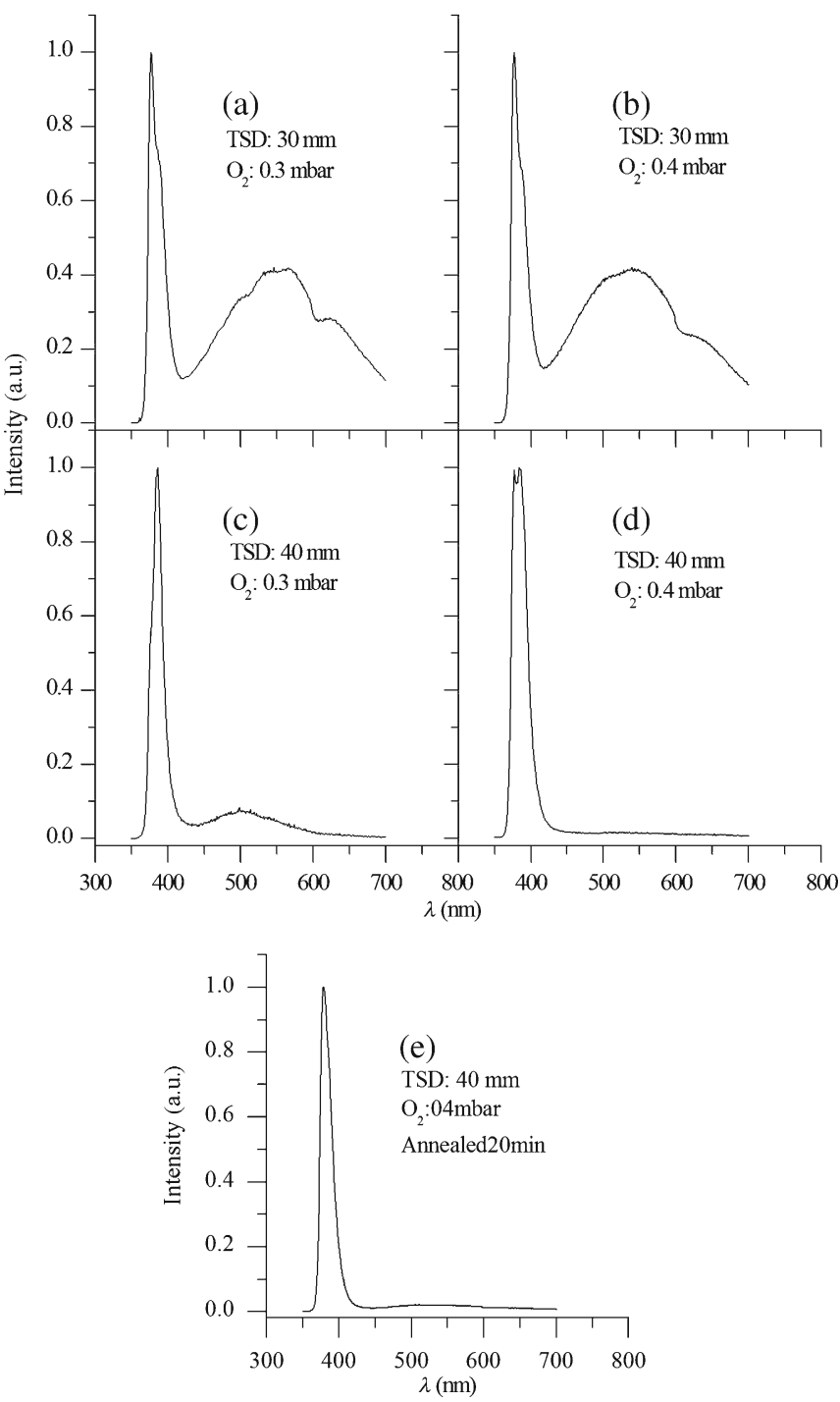

Figure 2. PL spectra of grown thin film with expected blue bandedge transition (about $370 \mathrm{~nm}$ ). Some of films present yellow-green and orange bands of 450-700 $\mathrm{nm}$ associated to lack of oxygen. Figures (a-d) correspond to as-grown films while figure (e) corresponds to a film annealed for $20 \mathrm{~min}$ with same oxygen pressure and temperature as used during its growth. 
and they are non-existant in the $\mathrm{ZnO}$ film prepared at this same TSD but at 0.4 mbar of oxygen pressure.

The annealing performed to films grown with same parameters as of figure 2(d) produced a deterioration of optical quality as can be observed by the presence of small yellowgreen band (see figure 2(e)).

Performed plasma analysis revealed that for any of the two used oxygen pressures, the established shock wave was decelerated to kinetic energies lower than $1 \mathrm{eV}$ after $20 \mathrm{~mm}$ of expansion. Inside the plasma plume, the plasma temperature was calculated to be of the order of $0.2-0.5 \mathrm{eV}$. Furthermore, over this distance, the ionization ratio of the produced plasma was very low. All these results rule out or reduce, to lower the probabilities of $\mathrm{ZnO}$ formation during the plasma expansion through one of the following reactions:

$$
\begin{aligned}
& \mathrm{Zn}^{+}+\mathrm{O}_{2} \rightarrow \mathrm{ZnO}^{+}+\mathrm{O}, \\
& \mathrm{Zn}^{*}+\mathrm{O}_{2} \rightarrow \mathrm{ZnO}+\mathrm{O}, \\
& \mathrm{Zn}+\mathrm{O}_{2}+e^{-} \rightarrow \mathrm{ZnO}+\mathrm{O}+e^{-},
\end{aligned}
$$

after accounting their energy thresholds.

Reaction (1) has been reported (Fisher et al 1990) to have a threshold of about $3 \mathrm{eV}$ and a maximum cross-section at $6 \mathrm{eV}$. Although no data was found for the energy requirement of reaction (2), it can be expected that the excitation of the atomic zinc should, at least, equal the dissociation energy of the oxygen molecule $(5 \cdot 12 \mathrm{eV})$ (Itikawa et al 1989). Similar energy requirement should be seen in the electron participating in reaction (3). It should be noticed that reactions with atomic oxygen can take place with the participation of a third body and that reaction (3) could be obtained as well with an energetic atom instead of an electron. In any case, energy requirements for participating atom or electron will be similar to the above mentioned reactions. The low probability of $\mathrm{ZnO}$ formation during the plasma phase was pointed out by other authors, which suggested that $\mathrm{Zn}$ nuclei oxidize on the substrate to form the final compound (Im et al 2000).

One possibility for such process to take place is assuming that a $\mathrm{Zn}$ thin film is deposited and then oxidized by oxygen atmosphere. For zinc oxidation at temperature between 370 and $415^{\circ} \mathrm{C}$, the weight gain per area $(l)$ in $\mathrm{g} / \mathrm{cm}^{2}$ of the forming oxide will follow a parabolic law as a function of time $(t)$ (Tuck et al 1981). It is defined as:

$$
\iota^{2}=\kappa_{\mathrm{p}} t,
$$

where $\kappa_{\mathrm{p}}$ is the parabolic constant. For the temperature and pressures used in our experiments, $\kappa_{\mathrm{p}} \approx 1.9 \times$ $10^{-15} \mathrm{~g}^{2} \mathrm{~cm}^{-4} \mathrm{~s}^{-1}$ (Tuck et al 1981). Calculation of (4) for $100 \mathrm{~ms}$, time between laser pulses and for $0.25 \mathrm{~cm}^{2}$ substrate area gives a weight gain of $3 \cdot 5 \times 10^{-9} \mathrm{~g}$. Using the

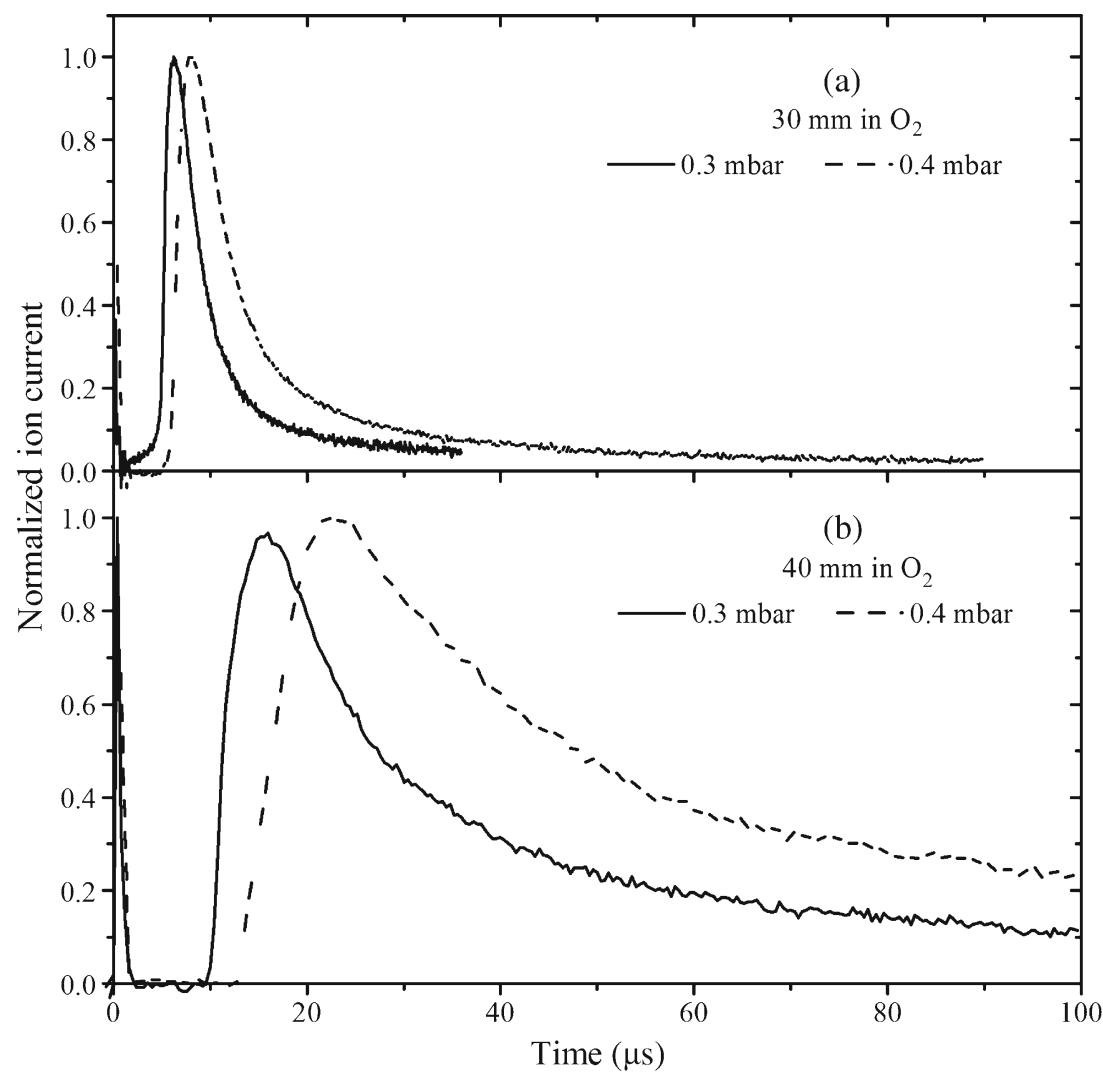

Figure 3. Ion currents measured using a planar Langmuir probe placed at same positions of substrates, (a) $30 \mathrm{~mm}$ and (b) $40 \mathrm{~mm}$. FWHM are (a) 4 and $6 \mu \mathrm{s}$ and (b) 16 and $31 \mu$ s for 0.3 and 0.4 mbar of $\mathrm{O}_{2}$, respectively. 
obtained average deposition rate, the substrate area and the $\mathrm{ZnO}$ bulk density $\left(5.6 \mathrm{~g} / \mathrm{cm}^{3}\right)$, the mass of oxide formed is $4.2 \times 10^{-9} \mathrm{~g} /$ pulse, which suggest that the above mentioned oxidation process may take place. Although, if this is so, the stoichiometry would be the same for all grown films.

Another possibility is that the oxide forms during plasma residence time. An estimate of this time can be obtained from the ion currents measured with the Langmuir probe, shown in figure 3. It can be observed that the plasma residence times, taken as the full width at half maximum of the curves, at a TSD of $40 \mathrm{~mm}$ are 4-5 times greater than those measured at a TSD of $30 \mathrm{~mm}$. This implies a reduction in the rate of arrival material, it is the amount of material that is deposited on the substrate over a period of time after one laser pulse. The lower the rate of arrival material, the greater the time and area the adatoms have for their surface diffusion. This of course increases the probability for both reaching sites of minimum energy and the collision of oxygen and zinc adatoms to form the oxide. All this will be translated into a growth with better stoichiometric properties and the formation of greater grains, which agree with the experimental results in this work.

A higher probability for oxide formation during dematerial arrival can be expected as well due to the presence of atomic oxygen formed during the target ablation. Atomic oxygen is a key element to allow the formation of $\mathrm{ZnO}$. The dissociation of molecular oxygen leads as well to atomic oxygen, but this is a slow process which furthermore involves the adsorption of the oxygen molecule to the surface of the film. The probability of such adsorption is known to be very low (Carley et al 2002).

Once the plasma plume moved away from the substrate position, the oxidation can take place as well but, the oxygen incorporation will be mainly due to the diffusion into the formed $\mathrm{ZnO}$ (Robin et al 1973). This is a process which involves interaction with defects and hole migration. The diffusion coefficient has been measured to vary from $4.9 \times$ $10^{-16}$ to $3.2 \times 10^{-15} \mathrm{~cm}^{2} / \mathrm{s}$ as temperature varies from 940 to $1141{ }^{\circ} \mathrm{C}$ at 700 torr of oxygen (Robin et al 1973). Diffusion data for lower pressures and temperatures are not available, but it is to be expected that there will be a decrease in the coefficient values. In general, depth of the diffusion will at most be of the order of Ångströms, which is only noticeable at earlier times of the growth when the film thickness is of this order.

\section{Conclusions}

In conclusion, low probability for $\mathrm{ZnO}$ formation during the plasma phase of PLD process is shown. It had been demonstrated that such formation takes place through the oxidation of $\mathrm{Zn}$ species on the substrate surface while the ablated material is being deposited. An important aspect is that to select a suitable combination of growth parameters as to maximize the time of residence of the plasma over the growing film. This reduces the rate of material arrival increasing the surface diffusion of adatoms and their interaction.

\section{Acknowledgements}

The authors thank CONACYT-Mexico, SIP-Instituto Politécnico Nacional-Mexico, EU Competitive and Sustainable Growth Program and Enterprise Ireland.

\section{References}

Carley A F, Davies P R and Roberts M W 2002 Catal. Lett. 8025

Claeyssens F, Freeman C L, Allan N L, Sun Y, Ashfold M N R and Harding J H 2005 J. Mater. Chem. 15139

Fisher E R, Elkind J L, Clemmer D E, Georgiadis R, Loh S K, Aristov N, Sunderlin L S and Armentrout P B 1990 J. Chem. Phys. 932676

Fukumura T, Jin Z, Ohtomo A, Koinuma H and Kawasaki M 1999 Appl. Phys. Lett. 753366

Im S, Jim B J and Yi S 2000 J. Appl. Phys. 874558

Itikawa Y, Ichimura A, Onda K, Sakimoto K and Takayanagi K 1989 J. Phys. Chem. Ref. Data 1823

Li Y Z, Li X M, Yang C, Gao X D and He Y 2010 J. Phys. D: Appl. Phys. 43285101

Robin R, Cooper A R and Heuer A H 1973 J. Appl. Phys. 44 3770

Shan F K, Liu G X, Lee W J, Lee G H, Kim I S and Shin B C 2005 Appl. Phys. Lett. 86221910

Shim S, Kang H S, Kang J S, Kim J H and Lee S Y 2002 Appl. Surf. Sci. 186474

Tang Z K, Wong G K L, Yu P, Kawasaki M, Ohtomo A, Koinuma H and Segawa Y 1998 Appl. Phys. Lett. 723270

Tobin G, McGlynn E, Henry M O, Mosnier J P, de Posada E and Lunney J G 2006 Appl. Phys. Lett. 88071919

Tuck C D S, Whitehead M E and Smallman R E 1981 Corros. Sci. 21333

Vasco E, Zaldo C and Vazquez L 2001 J. Phys.: Condens. Matter 13663

Wang P R, Zhou Y L, Pan S H, He M, Chen Z H and Yang G Z 1999 Physica C 32837

Wang R P, Muto H and Kusumori T 2003 Opt. Mater. 2315

Wu X L, Siu G G, Fu C L and Ong H C 2001 Appl. Phys. Lett. 78 2285

Xuan L Z, Pan S H, Chen Z H, Wang R P, Shi W S and Li C L 1998 Appl. Phys. Lett. 732896 